\title{
The Emerging Role and Promise of Long Noncoding RNAs in Lung Cancer Treatment
}

\author{
Ying Chen Chen Li Yan Pan Siqi Han Bing Feng Yanping Gao Jing Chen \\ Kai Zhang Rui Wang Longbang Chen \\ Department of Medical Oncology, Jinling Hospital, School of Medicine, Nanjing University, Nanjing, \\ China
}

\author{
Key Words \\ Long noncoding RNA • Lung cancer • Biomarker resistance
}

\begin{abstract}
Lung cancer is the leading cause of cancer death around the world. The advanced discovery of numerous long noncoding RNAs (IncRNAs) has dramatically changed the understanding of biology of human cancers, including lung cancer. LncRNAs are a group of noncoding RNAs (ncRNAs) with a length greater than 200 nucleotides with limited or no proteincoding capacity. Increasing evidence has shown that specific IncRNAs may be implicated in the process of tumorigenesis. Because of their roles in the regulation of multiple molecular pathways associated with changes in gene expression, IncRNAs can serve as potential diagnostic biomarkers or therapeutic targets in lung cancer. Importantly, dysregulated IncRNAs is reported to be correlated with the sensitivity of lung cancer cells to anticancer therapies, including chemotherapy, molecular-targeted therapy, etc. Herein, we review the recent progress of IncRNAs in lung cancer, with a particular focus on the multiple molecular roles of regulatory IncRNAs on the molecular signaling pathways involved in tumorigenesis and the resistance to such therapies.

\section{Introduction}

Lung cancer remains the most common cancer deaths worldwide and accounts for 19.4 $\%$ of total cancer mortality [1]. In industrialized countries, lung cancer is the leading cause of cancer death in males and is growing in incident rates among females [2]. More than half of all patients diagnosed with lung cancer are poor prognosis. Despite improvements in early diagnosis, advancements in treatment, five year survival rate for primary lung cancer remaining below $16 \%$ [3]. 
Primary lung cancers are traditionally classified as either small cell lung cancer (SCLC) or non-small cell lung cancer (NSCLC). NSCLC accounts for approximately $80 \%$ of all primary lung cancers with adenocarcinoma, squamous cell carcinoma and large cell carcinoma constituting the major histological types. At the time of diagnosis, almost half of NSCLC cases are localized or locally advanced, complete surgical resection remains the best option for these patients. However, for patients with advanced NSCLC, platinum-based combination chemotherapy is currently recommended as the standard treatment. With the increase in understanding of the biological mechanisms in lung cancer, molecular targeting treatment has achieved graveness progression and the curative effect was striking. The epidermal growth factor receptor $(E G F R)$ is seen as a promising target and frequently mutated in patients with NSCLC. EGFR-directed therapies and angiogenesis inhibitors have now emerged as the best options for these patients with a mutation in exons 19 or 21 of the EGFR [4]. In contrast, 80\% of patients with SCLC have metastatic disease at the time of diagnosis. SCLC is characterized by rapid growth rate, early regional lymph node metastasis, and spread to distant sites. Survival percentages for lung cancer is significantly low when only SCLC is considered [5]. For prognostic and therapeutic reasons, having a standardized and validated approach to stage the disease accurately is imperative.

Due to the development of resistance to therapies, the treatment of lung cancer faced a significant challenge [6]. Cancer drug resistance can be classified in two types: pre-existing and acquired [7]. Recent studies have demonstrated that intracellular signaling pathways play key physiological roles and the abnormal activation of signaling pathways may be correlated with acquired resistance. For example, RUNX3 confers, at least in part, resistance of lung adenocarcinoma cells to docetaxel (DTX) agent via activating AKT signaling [8]. In addition, dysregulated of ZEB1 and ING4 is also found to be involved in the resistance of lung adenocarcinoma cell to DTX $[9,10]$. Meanwhile, the dysregulation of ncRNAs has been highlighted as a novel mechanism of resistance in recent years.

\section{LncRNAs biogenesis and gene expression}

Over the last decade, advances in genome-wide analysis of gene expression have revealed that protein coding gene exons constitute less than $3 \%$ of the human genome, and a growing list of noncoding RNA genes within introns has been shown to regulate the expression of genes [11]. The ncRNAs composes three types: long ncRNAs, mid-size ncRNAs and short ncRNAs. Recently, the research of short ncRNAs has been the hotspot, such as microRNAs (miRNAs). MiRNAs are exciting molecular entities with additional advantages as targeting gene regulation to change the lung cancer treatment in the future. The association between altered let-7 family expression and the biological and clinical effects in lung cancer was first reported. Further study has found that restoration of Let-7c can reverse chemo- or radioresistance of lung adenocarcinoma cell via targeting Bcl-xL [12]. MiR-145 and miR-224 are reported to confer the chemoresistance of lung adenocarcinoma cells to cisplatin (CDDP) via delaying the progression of the cell cycle from $G 1$ to $S$ phase $[13,14]$. In addition, miR650 has been shown as a potential target for chemosensitizing lung adenocarcinoma cells to DTX and of interest, miR-451 play a role in both DTX or CDDP resistance and radioresistance $[15,16]$. These results clearly suggest that dysregulation of miRNAs is associated with the resistance of lung cancer to anti-cancer therapies have been reported. LncRNA, another novel class of ncRNA, is rapidly gained prominence and gives hope for a more profound understanding of lung cancer [17].

In general, IncRNAs are greater than 200 nucleotides with limited or no protein-coding capacity. In contrast to protein-coding genes, the transcription start sites of lncRNAs are around by a higher level of DNA methylation independent of their expression status, which makes a clear distinction between the two [18]. Transcription of lncRNAs occurs from an independent gene promoter and a large number of them are transcribed by RNA polymerase II. The act of some transcription is associated with epigenetic signatures common to protein- 
coding genes, such as trimethylation of histone 3 lysine 4 (H3K4me3) at the transcriptional start site and trimethylation of histone 3 lysine 36 (H3K36me3) throughout the gene body. The expression levels of many identified lncRNA appear to be lower than protein-coding genes, and some lncRNAs are frequently expressed in a tissue-specific manner [19].

Up to now, more than 3000 IncRNAs have been identified. It is not easy to generate comprehensive classifications of lncRNAs, because the same lncRNAs may be listed in different groups in all classifications. Derrien et al. subclassified lncRNAs according to their location with respect to the nearest protein-coding gene, and the categories include exonic lncRNAs (antisense/sense), intronic lncRNAs (antisense/sense), overlapping lncRNAs (antisense/ sense), and intergenic lncRNAs [20]. As localized to the nucleus, lncRNAs have the potential capabilities of modulating chromatin or functioning as genetic expression regulators. Aberrant expression of several lncRNAs is related to carcinogenesis, and dysregulation of them participate in tumor initiation, progression, and metastasis in various types of human cancers, such as gastric cardiac adenocarcinoma, breast cancer, hepatocellular carcinoma, etc [21-23]. LncRNAs regulate various molecular signaling pathways via changing gene expression, and therefore, dysregulation of their expression may be implicated in general mechanisms of carcinogenesis [24]. The expression level of lncRNAs has indeed shown significantly different between cancer tissues and normal tissues. HOTAIR (HOX transcript antisense RNA), MALAT1 (metastasis associated lung adenocarcinoma transcript 1), HOTTIP (HOXA transcript at the distal tip), ANRIL (antisense noncoding RNA in the INK4 locus), and ZXF2 have been found to be upregulated in lung cancer tissues, and upregulation of those lncRNAs is correlated with higher TNM stage, advanced lymph-node metastasis, and poorer overall survival of patients [25-30]. Meanwhile, plenty of tumor suppressive lncRNAs have been identified, such as MEG3 (maternally expressed gene 3), lincRNA-p21, GAS5 (growth arrest specific transcript 5), TUG1 (taurine-upregulated gene 1) [31-33]. Considering their roles in carcinogenesis, lncRNAs may hold promise as diagnostic or prognostic biomarkers for lung cancer [34].

\section{Roles of IncRNAs in lung cancer biology}

LncRNAs play important roles in many biological processes, such as transcription, splicing, translation, protein localization, epigenetic gene expression, ribonucleoprotein complexes, chromatin modifying enzymes, and so on [35-37] (Fig. 1). Because of their roles in the regulation of multiple molecular signaling pathways associated with changes in gene expression, lncRNAs are implicated in cancer progression implicated in the initiation and progression of lung cancer [38]. For example, MALAT1 is the first identified lung cancer-associated IncRNA, which promotes motility and proliferation of lung cancer cells by regulating caspase-8, caspase-3, BAX, BCL-2, and BCL-XL [39]. In the past decade, the increasing recognition of lncRNAs has defined these genes as critical actors in numerous cellular processes of lung cancer [40].

Fig. 1. The molecular mechanisms involved in action of IncRNAs. (A) LncRNAs can guide chromatin modifying enzymes to specific genomic loci target genes. (B) LncRNAs can bind to the promoter of genes and regulate their expression to mediate transcription pathway. (C) LncRNAs can recruit multiple proteins to form ribonucleoprotein complexes. (D) Some lncRNAs can be processed to miRNAs, or they can function as decoy for miRNA target sites. (E) LncRNAs can affect the stability of mRNAs via binding to its target mRNAs.

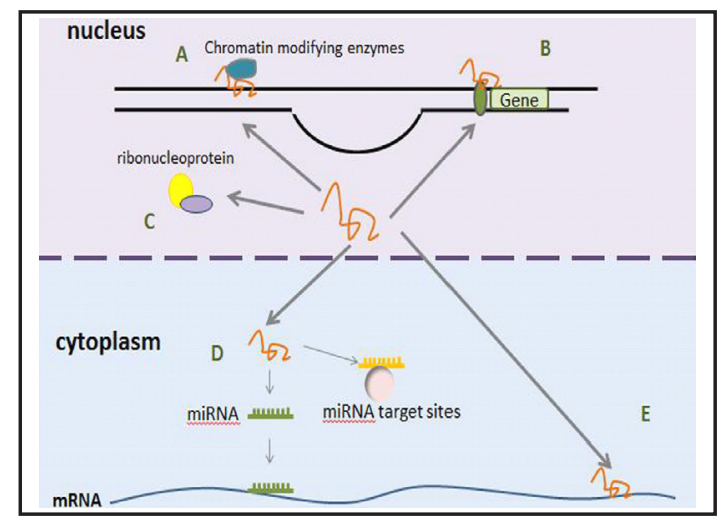




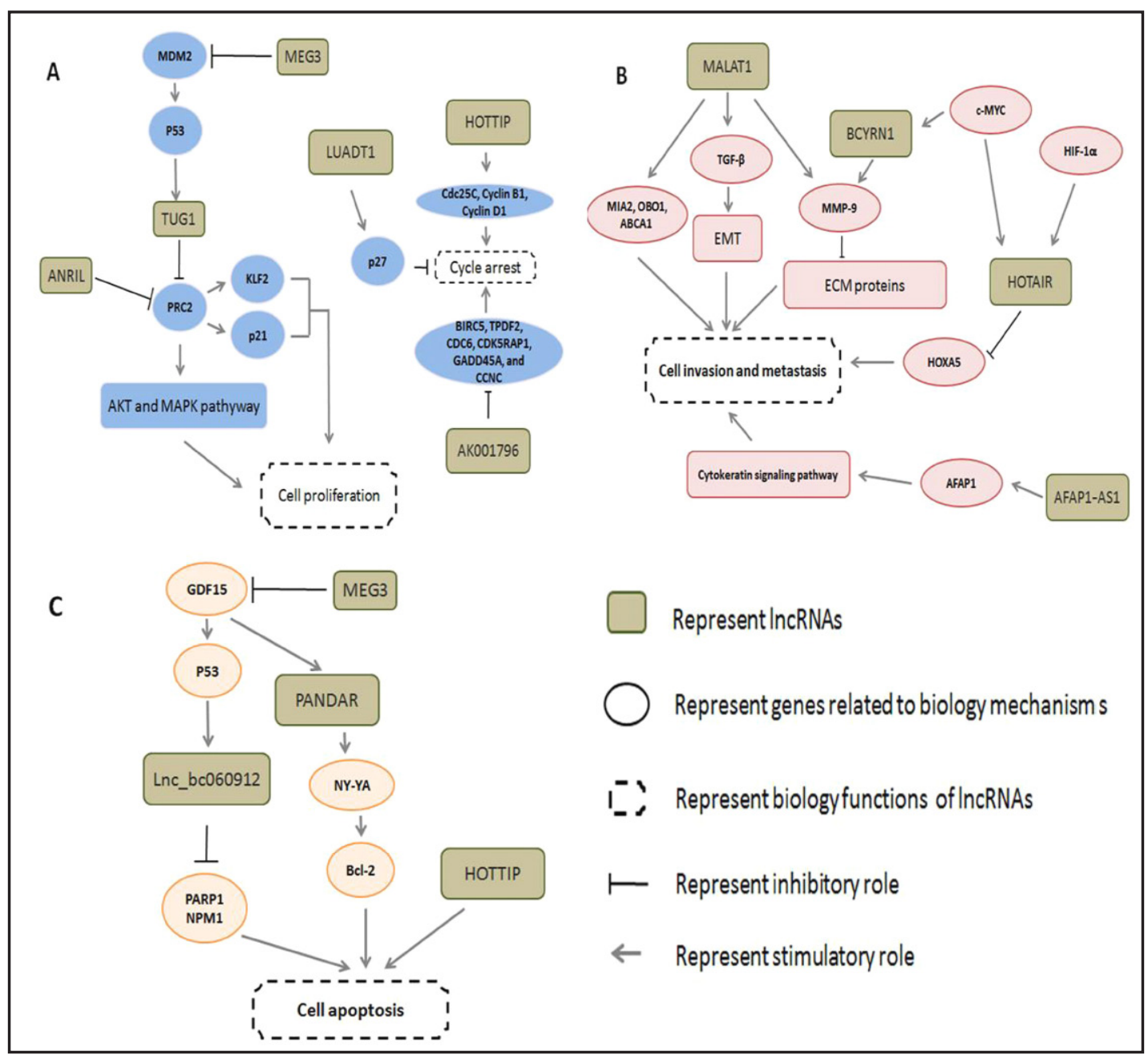

Fig. 2. Regulatory networks of special IncRNAs involved in the pathogenesis of lung cancer. (A) LncRNAs related to cell proliferation and survival pathways. (B) LncRNAs related to cell invasion and metastasis. (C) LncRNAs related to cell apoptosis.

\section{LncRNAs related to cell proliferation}

Multiple signaling pathways are activated and contribute to tumor cell survival and proliferation. To date, there are a number of research findings alluding to lncRNAs and cell proliferation in different cancer types, including lung cancer (Fig. 2A). Numerous lncRNAs have been reported as inducer of uncontrolled cell proliferation in lung cancer. Some of these examples include PANDAR (promoter of CDKN1A antisense DNA damage-activated RNA), which is demonstrated to repress the proliferation in vitro and in vivo of NSCLC cells when overexpressing [41].

Further experiments revealed that TUG1 (taurine-upregulated gene 1) is a direct transcriptional target of $p 53$. P53-regulated TUG1 is a growth regulator, which can bind to PRC2. Also, the promoter of HOXB7 locus could be bound by EZH2 (enhancer of zeste homolog 2), a key component of PRC2, suggesting that HOXB7 is a bona target of TUG1/PRC2regulated genes. This TUG1-mediated growth regulation is in part due to specific modulation of HOXB7, thus participating in AKT and MAPK pathways [33]. ANRIL, a lncRNA located in cell nucleus and silences KLF2 and $P 21$ by directly binding with EZH2, could promote the proliferation of NSCLC cells [29]. Phospholipase D (PLD) produces phosphatidic acid (PA), and aberrant PLD/PA signaling has been observed in various types of human cancers. Kang and his colleagues showed that ANRIL was responsible in anti-tumorigenesis caused by PLD 
inhibition, suggesting that combined incorporation of ANRIL into PLD inhibition-induced anti-tumorigenic signaling network could be a new effective therapeutic approach for controlling lung cancer [42].

Deng et al. found that depletion of HOTTIP not only caused cell cycle arrest in G0/ G1 phase but also inhibited tumor growth in a mouse model of lung cancer, which were correlated with upregulation of cell cycle regulators Cdc25C, Cyclin B1 and Cyclin D1 [28]. Identical to HOTTIP, IncRNA AK001796 could regulate the expression of different cell-cycleassociated genes, including BIRC5, TPDF2, CDC6, CDK5RAP1, GADD45A, and CCNC. TFDP2 encodes a protein that forms heterodimers with the E2F transcription factors, leading to the transcriptional activation of cell-cycle-regulated genes. CDC6 regulates the early steps of DNA replication. ATR is a cell-cycle-checkpoint gene responsible for cell-cycle arrest and DNA damage repair in response to DNA damage. Reduced AK001796 potentially causes a cell-cycle arrest, with significant increases in the percentage of cells in G0/G1 in lung cancer cells [43]. P27 as a tumor suppressor that regulates cell cycle proliferation can be a potential target of LUADT1 (lung adenocarcinoma transcript 1). Both in vitro and in vivo data showed that LUADT1 knockdown significantly inhibits cell proliferation and induces cell cycle arrest at the G0-G1 phase by epigenetically inhibiting the expression of $p 27[44,45]$.

Functional validation shows that the most differentially expressed lncRNA across lung subtypes, LCAL1 (lung cancer associated IncRNA 1), contributes to cellular proliferation [46]. Furthermore, siRNA-mediated knockdown of MVIH could inhibit cell growth via regulating MMP-2 and MMP-9 protein expression in NSCLC [47]. Likewise, silencing of CCAT2 (Colon cancer associated transcript 2) could lead to inhibition of proliferation in NSCLC cell lines in vitro [48]. $\mathrm{H} 19$, a functional executor of oncogene $c-M y c$ downstream, plays a key role in the development of lung cancer through affecting cell proliferation [49]. By contrast, MEG3 functions as a tumor suppressive IncRNA. Overexpression of MEG3 is found to induce the increased expression of MDM2 and p53 protein, and decreases NSCLC cells proliferation in vitro and impedes tumorigenesis in vivo [31]. These findings provide recent updates on the noncoding genetic targets for the prevention and treatment of lung cancer.

\section{LncRNAs related to cell invasion and metastasis}

Recent studies have demonstrated that abnormal expression of lncRNAs has been observed in tumor tissues, and dysregulation of numerous lncRNAs is correlated with poor prognosis in lung cancer. Studies examining the roles of lncRNAs in lung cancer development showed that ANRIL, HNF1A-AS1, PVT1, CARLo-5 and CCAT2 play important roles in migration and invasion in NSCLC cells [29, 48, 50-52]. In another study, in vitro experiments demonstrated that silencing of LINC01133 could significantly reduce the invasion ability of lung squamous cell cancer cells [53].

Elevated expression of IncRNA MALAT-1 has been observed in NSCLC, and are correlated with higher incidence of lymph node metastasis [54]. MALAT1, also known as NEAT2, is a highly conserved nuclear lncRNA and specifically enriched in nuclear speckles [55]. In lung cancer, MALAT1 actively regulates gene expression including a set of metastasisassociated genes independent of altering alternative splicing (Fig. 2B). It is known that aberrantly activated ERK/MAPK pathway contributes to cancer cell metastasis. Knockdown of MALAT-1 can downregulate the expression of MMP-9 and inactivate the extracellular signal-regulated kinase/ mitogen-activated protein kinase (ERK/MAPK) pathway. Also, lncRNA BCYRN1, which is the target of $c-M Y C$, could increase the expression of MMP-9 and MMP-13 and then lead to the increased capacities of cell motility and invasiveness in NSCLC [56]. Additionally, MALAT- 1 is reported to play an important part in TGF- $\beta$-induced EMT, which was a key step of cancer metastasis. Importantly, MALAT-1 could also regulate expression of several metastasis-associated genes including melanoma inhibitory activity 2 (MIA2, anegative regulator of tumor growth invasion), roundabout 1 (ROBO1, an inhibitor of glioma migration and invasion), glypican6 (GPC6, a promoter of breast cancer metastasis), ATP-bind cassette sub family A member 1 ( $A B C A 1$, an important factor for prostate cancer cell migration and epithelial-to-mesenchymal transition) [39]. Consequently, MALAT1 may

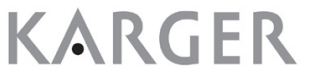


serve as an independent prognostic marker for patient survival and a potential therapeutic target in lung cancer.

Actin filament associated protein 1 antisense RNA1 (AFAP1-AS1) was reported to be the most significantly upregulated in lung cancer and associated with poor prognosis of patients. At the same time, in vitro functional experiments demonstrated that knockdown of AFAP1-AS1 significantly inhibited the invasive and migration capability of lung cancer cells by regulation of its antisense protein coding gene, actin filament associated protein 1 (AFAP1) and affecting the expression levels of several small GTPase family members and molecules in the actin cytokeratin signaling pathway [57].

HOTAIR, the IncRNA originally identified in breast cancer, was demonstrated to be upregulated in a variety of cancers includinglung cancer. This IncRNA is a HOXC cluster-derived lncRNA that binds to the transcriptional co-repressor PRC2 and recruits PRC2 to silence its target genes. Recent studies have identified that HOTAIR has an oncogenic role both in SCLC and NSCLC, and consistent with these observations, upregulation of HOTAIR could enhance the aggressive behaviors of lung cancer cells $[58,59]$. As the hypoxia-inducible lncRNA, HOTAIR is found to play an important role in hypoxia-enhanced aggressive phenotypes. HIF$1 \alpha$ targets HOTAIR through direct interaction with putative HREs in the upstream region of HOTAIR in NSCLC cells, and it is conceivable that myc mediates activation of the HOTAIR gene by Col-1 [60]. Under normoxic conditions, HIF-1 $\alpha$ does not activate HOTAIR transcription, but $c-M y c$ could be responsible for the transcriptional regulation of HOTAIR. Under hypoxic conditions, the hypoxia promotes c-Myc degradation and HIF- $1 \alpha$ could regulate HOTAIR expression, and then HOTAIR enhances cancer cell migration and invasion [61, 62]. HOXA5, a member of HOX family, has been reported to be involved in lung maturation and function. It was also found that inhibition of HOXA5 could significantly promote migration and invasion in A549 cells. In a study by Liu et al. showed that the oncogenic functions of HOTAIR may be partially exerted through downregulation of tumor suppressor HOXA5 [63]. Furthermore, another study indicates that HOTAIR can promote gelatinase activity in lung cancer cells by promoting the activity of MMP-9 and/or MMP-2, consistent with a role in promoting invasion and metastasis [64].

\section{LncRNAs related to cell apoptosis}

The same lncRNAs may induce different biologies in cancer cells via regulating the expression of different target genes (Fig. 2C). For example, depletion of HOTTIP not only causes cell cycle arrest in G0/G1 phase, but also induces significant cell apoptosis [28]. Moreover, MEG3 stimulates p53-dependent transcription by driving transcription of the growth differentiation factor 15 (GDF15), but not that of p21 [65, 66]. Thus, inhibition of lncRNA MEG3 leads to NSCLC cell proliferation and apoptosis, at least partially by preventing p53 activation. $P 53$, an important transcription factor, is capable of regulating the expression of many target genes and functioning as a tumor suppressor in tumor development. The mutation of p53 is often found in most human cancers, including lung cancer [67]. In contrary, p53 acts upstream of IncRNA Lnc_bc060912 in the regulatory network, and negatively regulates the expression of Lnc_bc060912, which represses cell apoptosis via interacting with the two DNA damage repair proteins PARP1 and NPM1 [68]. Also, overexpression of PANDAR significantly inhibits NSCLC cell growth in vitro and in vivo and enhances cell apoptosis partially via the transcriptional modulation of Bcl-2 by interacting with NF-YA, suggesting that dysregulation of the p53/PANDAR/NF-YA/Bcl-2 signaling axis might have a great effect on the progression and development of NSCLC [41].

\section{LncRNAs related to lung cancer therapy resistance}

LncRNAs related to cisplatin resistance in lung cancer

Cisplatin (CDDP) is a DNA-damaging cytotoxic agent, and represents a major landmark in the history of successful anticancer drugs since its clinical introduction in the 1970s [4]. Till 
now, CDDP-based treatment is also the golden standard for lung cancer treatment. However, the development of chemoresistance is the main cause of treatment failure. Recent studies suggest that lncRNAs also play a significant role in chemosensitivity and some lncRNAs has been reported to be associated with CDDP resistance in lung cancer. In a study by Hou et al., IncRNA AC006050.3-003 was observed to be correlated with the response of SCC patients to CDDP-based chemotherapy. Of course, further studies are warranted to elucidate the exact molecular mechanisms by which AC006050.3-003 functions in the response of SCC cells to CDDP [69]. CITED2, a transcriptional modulator, is involved in human oncogenesis, and the lncRNA-RP11-15H7.2 has been found to be located near it. CITED2 has been reported to be involved in the resistance of cancer cells to CDDP, raising the possibility that IncRNARP11-15H7.2 could be a promising new therapeutic target for overcoming the developing of resistance to CDDP in lung cancer [70].

The resistance of CDDP in lung cancer cells protects the cells from the cytotoxic effects of the drugs. $p 53$ is a DNA-binding tumor suppressor that plays a pivotal role in DNA repair and apoptosis, and CDDP can exert its cytotoxic effect partially through regulation of the p53 signaling pathway [71]. MEG3 activates the $p 53$ pathway via MDM2 suppression with consequent stimulation of GDF15 expression in turn, and finally leads to the suppression of cell proliferation. Cell cycle arrest is a critical process for DNA repair in CDDP-treated tumor cells, and therefore its failure may result in CDDP resistance. In a recent research, Liu et al. has found that MEG3 expression was markedly decreased in CDDP-resistant A549/DDP cells compared with parental A549 cells and its overexpression in A549/DDP cells increased their chemosensitivity to CDDP both in vitro and in vivo by inhibiting cell proliferation and inducing apoptosis [66]. As a member of the Bcl-2 family of proteins, Bcl-xl functions as suppressing tumor apoptosis, which is also reported to play an important role in mitochondrial permeabilization-induced apoptosis particularly through the p53-Bcl-xl interaction [71]. In this study, MEG3 was decreased in CDDP-insensitive lung adenocarcinoma tissues while p53 protein levels were decreased and Bcl-xl protein levels increased. These data demonstrated that MEG3 may regulate the CDDP resistance of lung adenocarcinoma cells through the control of p53 and Bcl-xl expression. P21 is a cyclin-dependent kinase inhibitor that is induced by p53 upon DNA damage or p53 overexpression, leading to inhibition of further cell proliferation by inducing cell cycle arrest at the G1 checkpoint. Low p21 expression has been found to promote the resistance of A549/DDP cells to CDDP. Epigenetic silencing is a common mechanism to inactivate tumor suppressor genes during carcinogenesis, and $p 21$ could be significantly increased in NSCLC cells after EZH2-siRNA delivery [72]. EZH2 is the components of PRC2, which works in cooperation with HOTAIR and participation in the modifications of DNA-binding proteins and then regulates global gene expression [58]. Therefore, knockdown of HOTAIR might re-sensitize the responses of A549/DDP cells to CDDP both in vitro and in vivo, at least partially through the regulation of $p 21$ expression [73]. LncRNA AK126698 is also reported to regulate the CDDP resistance of A549 cells partially through the canonical Wnt pathway. Wnt- $\beta$-catenin pathways are precisely controlled by a number of regulators, including the naked cuticle (NKD) family. Its two vertebrate orthologs NKD1 and NKD2 have been shown to negatively regulate canonical Wnt signaling by binding to Dvl. Knockdown of lncRNA AK126698 can significantly decrease the expression NKD2, which can negatively regulate Wnt/ $\beta$-catenin signaling. Meanwhile, knockdown of AK126698 could also increase the expression of whole $\beta$-catenin and nuclear translocation of $\beta$-catenin [74].

LncRNAs related to EGFR-TKIs resistance in lung cancer

The discovery of activating mutations in EGFR (exons 18-21) led to subsequent development of EGFR tyrosine kinase inhibitors (EGFR-TKIs), such as gefitinib and erlotinib, revolutionizing the treatment of lung carcinogenesis $[75,76]$. EGFR-TKIs are now recommended as first-line therapy for lung cancer patients with these mutations. Previous studies reported that the molecular mechanisms of EGFR-TKIs mainly includes activation of PI3K/Akt, MEK and STAT signal pathways, which promote cell proliferation and cell apoptosis 


\section{Cellular Physiology Cell Physiol Biochem 2016;38:2194-2206 and Biochemistry Published online: May 17, $2016 \quad \begin{aligned} & \text { DOI: 10.1159/000445575 } 2016 \text { The Author(s). Published by S. Karger AG, Basel } \\ & \text { www.karger.com/cpb }\end{aligned}$

Table 1. Biological functions of lncRNAs in lung cancer

\begin{tabular}{|c|c|c|c|}
\hline LncRNA & Functions of IncRNA & Target genes & References \\
\hline HOTAIR & $\begin{array}{l}\text { Promoting cell invasive and migration and } \\
\text { inducing chemoresistance }\end{array}$ & PRC2/HOXA5/MMP-9/MMP-2/p21 & {$[26,58,63,64,73]$} \\
\hline HOTTIP & $\begin{array}{l}\text { Promoting cell proliferation and inhibiting } \\
\text { apoptosis }\end{array}$ & Cdc25C/ Cyclin B1/Cyclin D1 & [28] \\
\hline ANRIL & Promoting cell proliferation & EZH2/PLD & {$[29,42]$} \\
\hline MEG3 & $\begin{array}{l}\text { Inhibiting cell proliferation, inducing cell } \\
\text { apoptosis and increasing chemosensitivity }\end{array}$ & MDM2/p53 & {$[31,65]$} \\
\hline TUG1 & Promoting cell proliferation & PRC2 & {$[33]$} \\
\hline MALAT-1 & $\begin{array}{l}\text { Promoting cell proliferation, invasive and } \\
\text { migration, and being involved in EGFR-TKIs } \\
\text { resistance }\end{array}$ & MMP-9/MIA2/ROB01/GPC6/ABCA1 & {$[39,54,82]$} \\
\hline PANDAR & $\begin{array}{l}\text { Inhibiting cell proliferation and inducing cell } \\
\text { apoptosis }\end{array}$ & NF-YA & [41] \\
\hline AK001796 & Promoting cell proliferation & $\begin{array}{l}\text { BIRC5/TPDF2/CDC6/CDK5RAP1/GA } \\
\text { DD45A/CCNC }\end{array}$ & {$[43]$} \\
\hline LUADT1 & Promoting cell proliferation & p27 & {$[44]$} \\
\hline MVIH & Promoting cell proliferation & MMP-2/MMP-9 & [47] \\
\hline HNF1A-AS1 & Promoting cell invasive and migration & Unclear & [50] \\
\hline PVT1 & Promoting cell invasive and migration & Unclear & [51] \\
\hline CARLo-5 & Promoting cell invasive and migration & Unclear & {$[52]$} \\
\hline BCYRN1 & Promoting cell invasive and migration & MMP-9/MMP-13 & [56] \\
\hline AFAP1-AS1 & Promoting cell invasive and migration & AFAP1 & [57] \\
\hline Lnc_bc060912 & Inhibiting cell apoptosis & PARP1/NPM1 & [68] \\
\hline AK126698 & Inhibiting CDDP resistance & NKD2 & [74] \\
\hline GAS5 & $\begin{array}{l}\text { Decreasing cell viability and resistance to EGFR- } \\
\text { TKIs }\end{array}$ & IGF-1R & [85] \\
\hline DLX6-AS1 & Promoting cell invasive and migration & Unclear & {$[86]$} \\
\hline HMlincRNA717 & Being involved in tumor progression & Unclear & {$[87]$} \\
\hline
\end{tabular}

in NSCLC $[77,78]$. Recently, more and more important regulatory functional lncRNAs are found to play critical roles in gefitinib-resistant lung cancer cells through regulation of cell proliferation and apoptosis.

EMT is a process where epithelial cells lose their cell polarity and cell-cell adhesion, and consequently with gaining migratory and invasive properties to become mesenchymal cells [79]. Increasing evidence show that EMT is associated with the resistance of lung cancer cells to EGFR-TKIs in vitro [80]. Recently, some lncRNAs have been reported to promote EGFR-TKIs resistance of lung cancer by regulating EMT process. As a member of the FOX transcription factor family, FOXC1 is important in cancer development and induces EMT via inhibiting E-cadherin expression and promotes cell migration and invasion [81]. LncRNAs BC087858 is an intergenic lncRNAs, which locates near forkhead box protein C1 (FOXC1). Thus, BC087858 may induce EGFR-TKIs resistance through EMT [78]. In addition, MALAT-1 is observed be downregulated in gefitinib-resistant lung cells. MALAT-1 is linked to EMTassociated transcription factors ZEB1, ZEB2, slug and E-cadherin, but whether MALAT-1 regulates EMT to affect the sensitivity of lung cancer cells to EGFR-TKIs is still unclear. Therefore, future studies are needed to fully elucidate the possible mechanisms of MALAT-1 involved in the development of EGFR-TKIs resistance [82].

Insulin-like growth factor 1 is an important growth regulatory pathway, significantly responsible for cancer cell proliferation, migration, and apoptosis [83]. Inhibition of IGF signaling, however, seems responsible for blocking the growth and survival of tumour cells where the PI3K-AKT or ERK pathways are activated by the loss of functional PTEN or RAS-RAF activation, respectively [84]. IGF-1 signaling is regulated by insulin-like growth factor 1 receptor (IGF-1R). IGF-1R has been identified as a downstream target of GAS5, and upregulation of GAS5 can decrease cell viability and reverse EGFR-TKIs resistance of lung cancer cells by directly downregulating IGF-1R expression [85].

\section{Discussion}

Since lncRNAs receive more and more attention, increasing numbers of lncRNAs associated with lung cancer have been identified. LncRNAs preferentially express in 


\section{Cellular Physiology Cell Physiol Biochem 2016;38:2194-2206 \begin{tabular}{ll|l} 
DOI: 10.1159/000445575 & O 2016 The Author(s). Published by S. Karger AG, Basel \\
www.karger.com/cpb
\end{tabular} \\ Chen et al.: LncRNAs: Potential Therapeutic Targets for Lung Cancer}

specific tissues and are related to differentiation status, lymph node metastases and TNM stage of patients. For example, high DLX6-AS1 expression level was closed correlated with both histological differentiation and TNM stage in lung adenocarcinoma [86]. Meanwhile, downregulation of HMlincRNA717 is reported to be involved in NSCLC progression [87]. These traits highlight the potential capability of IncRNAs to be an independent diagnostic or prognostic factor for lung cancer patients. Given the potential roles of lncRNAs in tumorigenesis, researchers have sought to identify lncRNAs which can be used for preventing or treating human cancers. Gutschner et al. reported that antisense oligonucleotides (ASO) -mediated blocking of MALAT1could prevent the metastasis formation after tumor implantation [88]. Meanwhile, targeting p53/TUG1/PRC2/HOXB7 or p53/PANDAR/NFYA/Bcl-2 signaling axis may be a promising strategy for the treatment of NSCLC $[33,41]$. These experimental data uncover that lncRNAs may serve as both predictive markers and therapeutic targets in lung cancer. The development of drug resistance remains as a major challenge in the treatment of lung cancer. Increasing evidence has pointed to the direct involvement of lncRNAs in the resistance of lung cancer to therapies (Table 1), suggesting that target lncRNAs may a potential strategy for reversing the resistance of lung cancers cell to chemotherapy and molecular-targeted therapy.

\section{Conclusions and Future Directions}

In conclusion, lncRNAs can serve as diagnostic or prognostic factors in lung cancer, while they are also such compelling molecular entities with the potential to offer a new approach to overcome the development of resistance in lung cancer treatment. However, the molecular mechanisms underlying the functions of IncRNAs are not yet fully understood, and the fundamental understanding of IncRNAs remains to be extended. Based on a deeper understanding of lncRNA biology in lung cancer, the lncRNA-based therapies in the form of ASOs as well as other technologies hold great promise for overcoming chemoresistance and developing more effective personalized anticancer treatment strategies in lung cancer patients. Before lncRNA-based therapies can become a successful method for the treatment of lung cancer patients, therapeutic delivery of delivery of target lncRNAs into tumor cells or tissues and evaluation of their safety still remain major challenges.

\section{Acknowledgements}

The work was supported by grants from the National Natural Science Foundation of China (No.81172335 and 81472266) and the Excellent Youth Foundation of Jiangsu Province, China (BK20140032).

\section{Disclosure Statement}

None.

\section{References}

1 Ferlay J, Soerjomataram I, Dikshit R, Eser S, Mathers C, Rebelo M, Parkin DM, Forman D, Bray F: Cancer incidence and mortality worldwide: sources, methods and major patterns in GLOBOCAN 2012. Int J Cancer 2015;136:E359-386.

2 Lam WK, White NW, Chan-Yeung MM: Lung cancer epidemiology and risk factors in Asia and Africa. Int J Tuberc Lung Dis 2004;8:1045-1057. 


\section{Cellular Physiology Cell Physiol Biochem 2016;38:2194-2206 \begin{tabular}{l|l} 
DOI: 10.1159/000445575 & $\begin{array}{l}\text { O 2016 The Author(s). Published by S. Karger AG, Basel } \\
\text { www.karger.com/cpb }\end{array}$
\end{tabular} \\ Chen et al.: LncRNAs: Potential Therapeutic Targets for Lung Cancer}

3 Chheang S, Brown K: Lung cancer staging: clinical and radiologic perspectives. Semin Intervent Radiol 2013;30:99-113.

4 Ramalingam SS, Owonikoko TK, Khuri FR: Lung cancer: New biological insights and recent therapeutic advances. CA Cancer J Clin 2011;61:91-112.

5 Davidson MR, Gazdar AF, Clarke BE: The pivotal role of pathology in the management of lung cancer. J Thorac Dis 2013;5:S463-478.

6 Xia H, Hui KM: Mechanism of Cancer Drug Resistance and the involvement of noncoding RNAs. Curr Med Chem 2014;21:3029-3041.

7 Kuczynski EA, Sargent DJ, Grothey A, Kerbel RS: Drug rechallenge and treatment beyond progressionimplications for drug resistance. Nat Rev Clin Oncol 2013;10:571-587.

8 Zheng Y, Wang R, Song HZ, Pan BZ, Zhang YW, Chen LB: Epigenetic downregulation of RUNX3 by DNA methylation induces docetaxel chemoresistance in human lung adenocarcinoma cells by activation of the AKT pathway. Int J Biochem Cell Biol 2013;45:2369-2378.

9 Ren J, Chen Y, Song H, Chen L, Wang R: Inhibition of ZEB1 reverses EMT and chemoresistance in docetaxelresistant human lung adenocarcinoma cell line. J Cell Biochem 2013;114:1395-1403.

10 Wang R, Huang J, Feng B, De W, Chen L: Identification of ING4 (inhibitor of growth 4) as a modulator of docetaxel sensitivity in human lung adenocarcinoma. Mol Med 2012;18:874-886.

11 Hangauer MJ, Vaughn IW, McManus MT: Pervasive transcription of the human genome produces thousands of previously unidentified long intergenic noncoding RNAs. PLoS Genet 2013;9:e1003569.

12 Cui SY, Huang JY, Chen YT, Song HZ, Feng B, Huang GC, Wang R, Chen LB, De W: Let-7c governs the acquisition of chemo- or radioresistance and epithelial-to-mesenchymal transition phenotypes in docetaxel-resistant lung adenocarcinoma. Mol Cancer Res 2013;11:699-713.

13 Wang H, Zhu LJ, Yang YC, Wang ZX, Wang R: MiR-224 promotes the chemoresistance of human lung adenocarcinoma cells to cisplatin via regulating G(1)/S transition and apoptosis by targeting p21(WAF1/ CIP1). Br J Cancer 2014;111:339-354.

14 Bar J, Gorn-Hondermann I, Moretto P, Perkins TJ, Niknejad N, Stewart DJ, Goss GD1, Dimitroulakos J4: miR Profiling Identifies Cyclin-Dependent Kinase 6 Downregulation as a Potential Mechanism of Acquired Cisplatin Resistance in Non-Small-Cell Lung Carcinoma. Clin Lung Cancer 2015;16:e121-129.

15 Wang R, Chen DQ, Huang JY, Zhang K, Feng B, Pan BZ, Chen J, De W, Chen LB: Acquisition of radioresistance in docetaxel-resistant human lung adenocarcinoma cells is linked with dysregulation of miR-451/c-Mycsurvivin/rad-51 signaling. Oncotarget 2014;5:6113-6129.

16 Huang JY, Cui SY, Chen YT, Song HZ, Huang GC, Feng B, Sun M, De W, Wang R, Chen LB: MicroRNA-650 was a prognostic factor in human lung adenocarcinoma and confers the docetaxel chemoresistance of lung adenocarcinoma cells via regulating Bcl-2/Bax expression. PLoS One 2013;8:e72615.

17 Yu H, Xu Q Liu F, Ye X, Wang J, Meng X: Identification and Validation of Long Noncoding RNA Biomarkers in Human Non-Small-Cell Lung Carcinomas. J Thorac Oncol 2015;10:645-654.

18 Wang Y, Qian CY, Li XP, Zhang Y, He H, Wang J, Chen J, Cui JJ, Liu R, Zhou H, Xiao L, Xu XJ, Zheng Y, Fu YL, Chen ZY, Chen X, Zhang W, Ye CC, Zhou HH, Yin JY, Liu ZQ: Genome-scale long noncoding RNA expression pattern in squamous cell lung cancer. Sci Rep 2015;5:11671.

19 Gibb EA, Brown CJ, Lam WL: The functional role of long non-coding RNA in human carcinomas. Mol Cancer 2011;10:38.

20 Derrien T, Johnson R, Bussotti G, Tanzer A, Djebali S, Tilgner H, Guernec G, Martin D, Merkel A, Knowles DG, Lagarde J, Veeravalli L, Ruan X, Ruan Y, Lassmann T, Carninci P, Brown JB, Lipovich L, Gonzalez JM, Thomas M, Davis CA, Shiekhattar R, Gingeras TR, Hubbard TJ, Notredame C, Harrow J, Guigó R: The GENCODE v7 catalog of human long noncoding RNAs: analysis of their gene structure, evolution, and expression. Genome Res 2012;22:1775-1789.

21 Wang Y, Gao S, Liu G, Jia R, Fan D, Feng X: Microarray expression profile analysis of long non-coding RNAs in human gastric cardiac adenocarcinoma. Cell Physiol Biochem 2014;33:1225-1238.

22 Chen J, Lin C, Yong W, Ye Y, Huang Z: Calycosin and genistein induce apoptosis by inactivation of HOTAIR/pAkt signaling pathway in human breast cancer MCF-7 cells. Cell Physiol Biochem 2015;35:722-728.

23 Li C, Chen J, Zhang K, Feng B, Wang R, Chen L: Progress and Prospects of Long Noncoding RNAs (lncRNAs) in Hepatocellular Carcinoma. Cell Physiol Biochem 2015;36:423-434. 


\section{Cellular Physiology Cell Physiol Biochem 2016;38:2194-2206

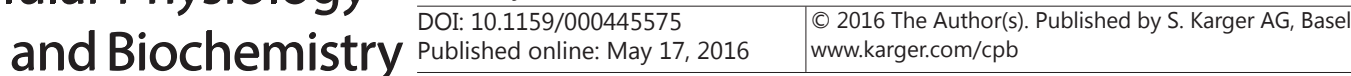 \\ Chen et al.: LncRNAs: Potential Therapeutic Targets for Lung Cancer}

24 Meseure D, Drak Alsibai K, Nicolas A, Bieche I, Morillon A: Long Noncoding RNAs as New Architects in Cancer Epigenetics, Prognostic Biomarkers, and Potential Therapeutic Targets. Biomed Res Int 2015;2015:320214.

25 Wu T, Yin X, Zhou Y, Wang Z, Shen S, Qiu Y, Sun R, Zhao Z: Roles of noncoding RNAs in metastasis of nonsmall cell lung cancer: A mini review. J Cancer Res Ther 2015;11:c7-c10.

26 Loewen G, Jayawickramarajah J, Zhuo Y, Shan B: Functions of lncRNA HOTAIR in lung cancer. J Hematol Oncol 2014;7:90.

27 Zhang J, Zhang B, Wang T, Wang H: LncRNA MALAT1 overexpression is an unfavorable prognostic factor in human cancer: evidence from a meta-analysis. Int J Clin Exp Med 2015;8:5499-5505

28 Deng HP, Chen L, Fan T, Zhang B, Xu Y, Geng Q: Long non-coding RNA HOTTIP promotes tumor growth and inhibits cell apoptosis in lung cancer. Cell Mol Biol (Noisy-le-grand) 2015;61:34-40.

29 Nie Fq, Sun M, Yang Js, Xie M, Xu Tp, Xia R, Liu YW, Liu XH, Zhang EB, Lu KH, Shu YQ: Long Noncoding RNA ANRIL Promotes Non-Small Cell Lung Cancer Cell Proliferation and Inhibits Apoptosis by Silencing KLF2 and P21 Expression. Mol Cancer Ther 2014;14:268-277.

30 Yang ZT, Li Z, Wang XG, Tan T, Yi F, Zhu H, Zhao JP, Zhou XF: Overexpression of Long Non-Coding RNA ZXF2 Promotes Lung Adenocarcinoma Progression Through c-Myc Pathway. Cell Physiol Biochem 2015;35:2360-2370.

31 Lu KH, Li W, Liu XH, Sun M, Zhang ML, Wu WQ Xie WP, Hou YY: Long non-coding RNA MEG3 inhibits NSCLC cells proliferation and induces apoptosis by affecting p53 expression. BMC Cancer 2013;13:461.

32 Pickard MR, Mourtada-Maarabouni M, Williams GT: Long non-coding RNA GAS5 regulates apoptosis in prostate cancer cell lines. Biochim Biophys Acta 2013;1832:1613-1623.

33 Zhang EB, Yin DD, Sun M, Kong R, Liu XH, You LH, Han L, Xia R, Wang KM, Yang JS, De W, Shu YQ Wang ZX: P53-regulated long non-coding RNA TUG1 affects cell proliferation in human non-small cell lung cancer, partly through epigenetically regulating HOXB7 expression. Cell Death Dis 2014;5:e1243.

34 Sang H, Liu H, Xiong P, Zhu M: Long non-coding RNA functions in lung cancer. Tumour Biol 2015;36:40274037.

35 Spizzo R, Almeida MI, Colombatti A, Calin GA: Long non-coding RNAs and cancer: a new frontier of translational research? Oncogene 2012;31:4577-4587.

36 Li CH, Chen Y: Targeting long non-coding RNAs in cancers: progress and prospects. Int J Biochem Cell Biol 2013;45:1895-1910.

37 Zhou M, Guo M, He D, Wang X, Cui Y, Yang H, Hao D, Sun J: A potential signature of eight long non-coding RNAs predicts survival in patients with non-small cell lung cancer. J Transl Med 2015;13:231.

38 Li M, Qiu M, Xu Y, Mao Q, Wang J, Dong G, Xia W1,2, Yin R5, Xu L6: Differentially expressed protein-coding genes and long noncoding RNA in early-stage lung cancer. Tumour Biol 2015;36:9969-9978.

39 Schmidt LH, Spieker T, Koschmieder S, Schäffers S, Humberg J, Jungen D, Bulk E, Hascher A, Wittmer D, Marra A, Hillejan L, Wiebe K, Berdel WE, Wiewrodt R, Muller-Tidow C: The long noncoding MALAT-1 RNA indicates a poor prognosis in non-small cell lung cancer and induces migration and tumor growth. J Thorac Oncol 2011;6:1984-1992.

40 Prensner JR, Chinnaiyan AM: The emergence of lncRNAs in cancer biology. Cancer Discov 2011;1:391-407.

41 Han L, Zhang EB, Yin DD, Kong R, Xu TP, Chen WM, Xia R, Shu YQ, De W: Low expression of long noncoding RNA PANDAR predicts a poor prognosis of non-small cell lung cancer and affects cell apoptosis by regulating Bcl-2. Cell Death Dis 2015;6:e1665.

42 Kang YH, Kim D, Jin EJ: Down-regulation of Phospholipase D Stimulates Death of Lung Cancer Cells Involving Up-regulation of the Long ncRNA ANRIL. Anticancer Res 2015;35:2795-2803.

43 Yang Q Xu E, Dai J, Liu B, Han Z, Wu J, Zhang S, Peng B, Zhang Y, Jiang Y: A novel long noncoding RNA AK001796 acts as an oncogene and is involved in cell growth inhibition by resveratrol in lung cancer. Toxicol Appl Pharmacol 2015;285:79-88.

44 Qiu M, Xu Y, Wang J, Zhang E, Sun M, Zheng Y, Li M, Xia W, Feng D, Yin R, Xu L: A novel lncRNA, LUADT1, promotes lung adenocarcinoma proliferation via the epigenetic suppression of p27. Cell Death Dis 2015;6:e1858.

45 Shen J, Yin JY, Li XP, Liu ZQ Wang Y, Chen J, Qu J, Xu XJ, McLeod HL, He YJ, Xia K, Jia YW, Zhou HH: The Prognostic Value of Altered eIF3a and Its Association with p27 in Non-Small Cell Lung Cancers. PLoS One 2014;9:e96008. 


\section{Cellular Physiology Cell Physiol Biochem 2016;38:2194-2206 \begin{tabular}{l|l|l}
\hline DOI: 10.1159/000445575 & $\begin{array}{l}\text { (c) 2016 The Author(s). Published by S. Karger AG, Basel } \\
\text { www.karger.com/cpb }\end{array}$
\end{tabular} \\ Chen et al.: LncRNAs: Potential Therapeutic Targets for Lung Cancer}

46 White NM, Cabanski CR, Silva-Fisher JM, Dang HX, Govindan R, Maher CA: Transcriptome sequencing reveals altered long intergenic non-coding RNAs in lung cancer. Genome Biol 2014;15:429.

47 Nie FQ Zhu Q, Xu TP, Zou YF, Xie M, Sun M, Xia R, Lu KH: Long non-coding RNA MVIH indicates a poor prognosis for non-small cell lung cancer and promotes cell proliferation and invasion. Tumour Biol 2014;35:7587-7594.

48 Qiu M, Xu Y, Yang X, Wang J, Hu J, Xu L, Yin R: CCAT2 is a lung adenocarcinoma-specific long non-coding RNA and promotes invasion of non-small cell lung cancer. Tumour Biol 2014;35:5375-5380.

49 Zhang E, Li W, Yin D, De W, Sun S, Han L: c-Myc-regulated long non-coding RNA H19 indicates a poor prognosis and affects cell proliferation in non-small-cell lung cancer. Tumour Biol 2016;37:4007-4015.

50 Yang X, Song JH, Cheng Y, Wu W, Bhagat T, Yu Y, Abraham JM, Ibrahim S, Ravich W, Roland BC, Khashab M, Singh VK, Shin EJ, Yang X, Verma AK, Meltzer SJ, Mori Y: Long non-coding RNA HNF1A-AS1 regulates proliferation and migration in oesophageal adenocarcinoma cells. Gut 2014;63:881-890.

51 Yang YR, Zang SZ, Zhong CL, Li YX, Zhao SS, Feng XJ: Increased expression of the lncRNA PVT1 promotes tumorigenesis in non-small cell lung cancer. Int J Clin Exp Pathol 2014;7:6929-6935.

52 Luo J, Tang L, Zhang J, Ni J, Zhang HP, Zhang L, Xu JF, Zheng D: Long non-coding RNA CARLo-5 is a negative prognostic factor and exhibits tumor pro-oncogenic activity in non-small cell lung cancer. Tumour Biol 2014;35:11541-11549.

53 Zhang J, Zhu N, Chen X: A novel long noncoding RNA LINC01133 is upregulated in lung squamous cell cancer and predicts survival. Tumour Biol 2015:36:7465-7471.

54 Zhu L, Liu J, Ma S, Zhang S: Long Noncoding RNA MALAT-1 Can Predict Metastasis and a Poor Prognosis: a Meta-Analysis. Pathol Oncol Res 2015;21:1259-1264.

55 Spector DL, Lamond AI: Nuclear Speckles. Cold Spring Harb Perspect Biol 2010;3:a000646-a000646.

56 Hu T, Lu YR: BCYRN1, a c-MYC-activated long non-coding RNA, regulates cell metastasis of non-small-cell lung cancer. Cancer Cell Int 2015;15:36.

57 Zeng Z, Bo H, Gong Z, Lian Y, Li X, Li X, Zhang W, Deng H, Zhou M, Peng S, Li G, Xiong W: AFAP1-AS1, a long noncoding RNA upregulated in lung cancer and promotes invasion and metastasis. Tumour Biol 2016;37:729-737.

58 Ono H, Motoi N, Nagano H, Miyauchi E, Ushijima M, Matsuura M, Okumura S, Nishio M, Hirose T, Inase N, Ishikawa Y: Long noncoding RNA HOTAIR is relevant to cellular proliferation, invasiveness, and clinical relapse in small-cell lung cancer. Cancer Med 2014;3:632-642.

59 Nakagawa T, Endo H, Yokoyama M, Abe J, Tamai K, Tanaka N, Sato I, Takahashi S, Kondo T, Satoh K: Large noncoding RNA HOTAIR enhances aggressive biological behavior and is associated with short disease-free survival in human non-small cell lung cancer. Biochem Biophys Res Commun 2013;436:319-324.

60 Zhuang Y, Wang X, Nguyen HT, Zhuo Y, Cui X, Fewell C, Flemington EK, Shan B: Induction of long intergenic non-coding RNA HOTAIR in lung cancer cells by type I collagen. J Hematol Oncol 2013;6:35.

61 Gloss BS, Dinger ME: The specificity of long noncoding RNA expression. Biochim Biophys Acta 2016;1859:16-22.

62 Zhou C, Ye L, Jiang C, Bai J, Chi Y, Zhang H: Long noncoding RNA HOTAIR, a hypoxia-inducible factor-1 $\alpha$ activated driver of malignancy, enhances hypoxic cancer cell proliferation, migration, and invasion in nonsmall cell lung cancer. Tumor Biology 2015;36:9179-9188

63 Liu XH, Liu ZL, Sun M, Liu J, Wang ZX, De W: The long non-coding RNA HOTAIR indicates a poor prognosis and promotes metastasis in non-small cell lung cancer. BMC Cancer 2013;13:464.

64 Zhao W, An Y, Liang Y, Xie XW: Role of HOTAIR long noncoding RNA in metastatic progression of lung cancer. Eur Rev Med Pharmacol Sci 2014;18:1930-1936.

65 Benetatos L, Vartholomatos G, Hatzimichael E: MEG3 imprinted gene contribution in tumorigenesis. Int J Cancer 2011;129:773-779.

66 Liu J, Wan L, Lu K, Sun M, Pan X, Zhang P, Lu B, Liu G, Wang Z: The Long Noncoding RNA MEG3 Contributes to Cisplatin Resistance of Human Lung Adenocarcinoma. PLoS One 2015;10:e0114586.

67 Zhao XY, Lin JD: Long Noncoding RNAs: A New Regulatory Code in Metabolic Control. Trends Biochem Sci 2015;40:586-596.

68 Luo H, Sun Y, Wei G, Luo J, Yang X, Liu W, Guo M, Chen R: Functional Characterization of Long Noncoding RNA Lnc_bc060912 in Human Lung Carcinoma Cells. Biochemistry 2015;54:2895-2902. 


\section{Cellular Physiology Cell Physiol Biochem 2016;38:2194-2206 and Biochemistry \begin{tabular}{l|l} 
DOI: 10.1159/000445575 & $\begin{array}{l}\text { (c) } 2016 \text { The Author(s). Published by S. Karger AG, Basel } \\
\text { www.karger.com/cpb }\end{array}$
\end{tabular} \\ Chen et al.: LncRNAs: Potential Therapeutic Targets for Lung Cancer}

69 Hou Z, Xu C, Xie H, Xu H, Zhan P, Yu L, Fang X: Long noncoding RNAs expression patterns associated with chemo response to cisplatin based chemotherapy in lung squamous cell carcinoma patients. PLoS One 2014;9:e108133.

70 Wang Y, Chen W, Yang C, Wu W, Wu S, Qin X, Li X: Long non-coding RNA UCA1a(CUDR) promotes proliferation and tumorigenesis of bladder cancer. Int J Oncol 2012;41:276-284.

71 Wang S, Li W, Xue Z, Lu Y, Narsinh K, Fan W, Li X, Bu Q, Wang F, Liang J, Wu K, Cao F: Molecular imaging of p53 signal pathway in lung cancer cell cycle arrest induced by cisplatin. Mol Carcinog 2013;52:900-907.

72 Cao W, Ribeiro Rde O, Liu D, Saintigny P, Xia R, Xue Y, Lin R, Mao L, Ren H: EZH2 promotes malignant behaviors via cell cycle dysregulation and its mRNA level associates with prognosis of patient with nonsmall cell lung cancer. PLoS One 2012;7:e52984.

73 Liu Z, Sun M, Lu K, Liu J, Zhang M, Wu W, De W, Wang Z, Wang R: The long noncoding RNA HOTAIR contributes to cisplatin resistance of human lung adenocarcinoma cells via downregualtion of p21(WAF1/ CIP1) expression. PLoS One 2013;8:e77293.

74 Yang Y, Li H, Hou S, Hu B, Liu J, Wang J: The noncoding RNA expression profile and the effect of lncRNA AK126698 on cisplatin resistance in non-small-cell lung cancer cell. PLoS One 2013;8:e65309.

75 Mok TS, Wu YL, Thongprasert S, Yang CH, Chu DT, Saijo N, Sunpaweravong P, Han B, Margono B, Ichinose Y, Nishiwaki Y, Ohe Y, Yang JJ, Chewaskulyong B, Jiang H, Duffield EL, Watkins CL, Armour AA, Fukuoka M: Gefitinib or Carboplatin-Paclitaxel in Pulmonary Adenocarcinoma. N Engl J Med 2009;361:947-957.

76 Maemondo M, Inoue A, Kobayashi K, Sugawara S, Oizumi S, Isobe H, Gemma A, Harada M, Yoshizawa H, Kinoshita I, Fujita Y, Okinaga S, Hirano H, Yoshimori K, Harada T, Ogura T, Ando M, Miyazawa H, Tanaka T, Saijo Y, Hagiwara K, Morita S, Nukiwa T; North-East Japan Study Group: Gefitinib or chemotherapy for nonsmall-cell lung cancer with mutated EGFR. N Engl J Med 2010;362:2380-2388.

77 Li H, Schmid-Bindert G, Wang D, Zhao Y, Yang X, Su B, Zhou C: Blocking the PI3K/AKT and MEK/ERK signaling pathways can overcome gefitinib-resistance in non-small cell lung cancer cell lines. Adv Med Sci 2011;56:275-284.

78 Sordella R1, Bell DW, Haber DA, Settleman J: Gefitinib-sensitizing EGFR mutations in lung cancer activate anti-apoptotic pathways. Science 2004;305:1163-1167.

79 Xia L, Huang W, Tian D, Zhu H, Qi X, Chen Z, Zhang Y, Hu H, Fan D, Nie Y, Wu K: Overexpression of forkhead box $\mathrm{C} 1$ promotes tumor metastasis and indicates poor prognosis in hepatocellular carcinoma. Hepatology 2013;57:610-624.

80 Uramoto H, Iwata T, Onitsuka T, Shimokawa H, Hanagiri T, Oyama T: Epithelial-Mesenchymal Transition in EGFR-TKI Acquired Resistant Lung Adenocarcinoma. Anticancer Res 2010;30:2513-2517.

81 Iwatsuki M, Mimori K, Yokobori T, Ishi H, Beppu T, Nakamori S, Baba H, Mori M: Epithelial-mesenchymal transition in cancer development and its clinical significance. Cancer Sci 2010;101:293-299.

82 Cheng N, Li X, Zhao C, Ren S, Chen X, Cai W, Zhao M, Zhang Y, Li J, Wang Q, Zhou C: Microarray expression profile of long non-coding RNAs in EGFR-TKIs resistance of human non-small cell lung cancer. Oncol Rep 2015;33:833-839.

83 Reinmuth N, Kloos S, Warth A, Risch A, Muley T, Hoffmann H, Thomas M, Meister M: Insulin-like growth factor 1 pathway mutations and protein expression in resected non-small cell lung cancer. Hum Pathol 2014;45:1162-1168.

84 Agulló-Ortuño MT1, Díaz-García CV, Agudo-López A, Pérez C, Cortijo A, Paz-Ares L, López-Ríos F, Pozo F, de Castro J, Cortés-Funes H, López Martín JA: Relevance of insulin-like growth factor 1 receptor gene expression as a prognostic factor in non-small-cell lung cancer. J Cancer Res Clin Oncol 2015;141:43-53.

85 Dong S, Qu X, Li W, Zhong X, Li P, Yang S, Chen X, Shao M, Zhang L: The long non-coding RNA, GAS5, enhances gefitinib-induced cell death in innate EGFR tyrosine kinase inhibitor-resistant lung adenocarcinoma cells with wide-type EGFR via downregulation of the IGF-1R expression. J Hematol Oncol 2015;8:43.

86 Li J, Li P, Zhao W, Yang R, Chen S, Bai Y, Dun S, Chen X, Du Y, Wang Y, Zang W, Zhao G, Zhang G: Expression of long non-coding RNA DLX6-AS1 in lung adenocarcinoma. Cancer Cell Int 2015;15:48.

87 Xie X, Liu HT, Mei J, Ding FB, Xiao HB, Hu FQ, Hu R, Wang MS: LncRNA HMlincRNA717 is down-regulated in non-small cell lung cancer and associated with poor prognosis. Int J Clin Exp Pathol 2014;7:8881-8886.

88 Gutschner T, Hämmerle M, Diederichs S: MALAT1 - a paradigm for long noncoding RNA function in cancer. J Mol Med (Berl) 2013;91:791-801. 